\title{
Protein import into isolated pea root leucoplasts
}

\author{
Chiung-Chih Chu and Hsou-min Li* \\ Institute of Molecular Biology, Academia Sinica, Taipei, Taiwan
}

Leucoplasts are important organelles for the synthesis and storage of starch, lipids and proteins. However, molecular mechanism of protein import into leucoplasts and how it differs from that of import into chloroplasts remain unknown. We used pea seedlings for both chloroplast and leucoplast isolations to compare within the same species. We further optimized the isolation and import conditions to improve import efficiency and to permit a quantitative comparison between the two plastid types. The authenticity of the import was verified using a mitochondrial precursor protein. Our results show that, when normalized to Toc75, most translocon proteins are less abundant in leucoplasts than in chloroplasts. A precursor shown to prefer the receptor Toc132 indeed had relatively more similar import efficiencies between chloroplasts and leucoplasts compared to

OPEN ACCESS

Edited by: Bo Liu,

University of California, Davis, USA

Reviewed by: Kentaro Inoue,

University of California, Davis, USA Danny Schnell,

University of Massachusetts, USA

*Correspondence: Hsou-min Li, Institute of Molecular Biology, Academia Sinica, Nankang, Taipei 11529, Taiwan mbhmli@gate.sinica.edu.tw

Specialty section: This article was submitted to Plant Cell Biology, a section of the journal

Frontiers in Plant Science

Received: 26 June 2015 Accepted: 20 August 2015 Published: 04 September 2015

Citation:

Chu C-C and Li H-m (2015) Protein import into isolated pea root leucoplasts.

Front. Plant Sci. 6:690. doi: 10.3389/fpls.2015.00690 precursors that prefer Toc159. Furthermore we found two precursors that exhibited very high import efficiency into leucoplasts. Their transit peptides may be candidates for delivering transgenic proteins into leucoplasts and for analyzing motifs important for leucoplast import.

\section{Keywords: leucoplasts, plastid, root, protein import, translocon}

\section{Introduction}

Plastids are essential plant organelles responsible for functions ranging from photosynthesis and biosynthesis of amino acids and fatty acids to assimilation of nitrogen and sulfur (Leister, 2003; Sakamoto et al., 2008). All plastids are derived from embryonic proplastids and differentiate into different functional types in different tissues, for example chloroplasts in green tissues for photosynthesis, chromoplasts in petals and fruits for carotenoid pigment accumulation, and leucoplasts in non-green tissues for nutrient storage (Wise, 2006). To perform these specific functions, different plastid types require different proteins (Kleffmann et al., 2007; Brautigam and Weber, 2009; Barsan et al., 2012).

Although plastids have their own genome, most plastid proteins are encoded by the nuclear genome and synthesized in the cytosol as a larger precursor with an $\mathrm{N}$-terminal extension called the transit peptide. Almost all of our current understanding of the molecular mechanism of plastid protein import is derived from studies with chloroplasts. Import across the chloroplast envelope membranes is mediated by the TOC and TIC (translocon at the outer/inner envelope membrane of chloroplasts) machinery. More than fifteen TOC and TIC components have been identified. Among them, Toc159 and Toc34 are receptors mediating the initial binding of precursor proteins to chloroplasts. Toc75 functions as the channel for protein translocation across the outer membrane. Major components of the TIC machinery includes Tic110 and the 1-MDa channel complex containing Tic20, Tic56, Tic100, and Tic214. Tic110 functions as the stromal site receptor for transit peptides and to act as a scaffold for tethering other translocon components located in the 
stroma. Hsp93, Hsp90C, and cpHsc70 are three chaperone motors important for the translocation of proteins into the stroma. Tic40 is a co-chaperone coordinating the actions of Tic110 and Hsp93 (for reviews see Li and Chiu, 2010; Shi and Theg, 2013; Paila et al., 2015).

The Arabidopsis Toc159 proteins are encoded by a four-gene family: Toc159, Toc132, Toc120, and Toc90. Toc159 and Toc132 are the major isoforms, with Toc90 and Toc120 as their functional redundant homologs, respectively. Toc159 preferentially binds transit peptides of photosynthetic proteins while Toc132 seems to prefer transit peptides of housekeeping proteins. Therefore, even though their substrate preference is not absolute, it is generally thought that Toc159 is the major receptor for photosynthetic proteins while Toc132 is important in mediating the import of non-photosynthetic housekeeping proteins into chloroplasts (Bauer et al., 2002; Ivanova et al., 2004; Kubis et al., 2004; Smith et al., 2004; Inoue et al., 2010; Bischof et al., 2011).

Leucoplasts are colorless, non-pigment-containing plastids. They are usually found in storage tissues and include the starch-storing amyloplasts, oil- and lipid-storing elaioplasts and protein-storing proteinoplasts (Wise, 2006). Most grainand root-type food crops use leucoplasts to synthesize and store the nutrients that are used to feed the majority of the world population. However, despite the economic importance of leucoplasts, little is known about how proteins are imported into leucoplasts. It has been speculated that leucoplasts may use a similar basic import mechanism to that of chloroplasts (Jarvis and Lopez-Juez, 2013) but leucoplasts clearly have a preference for importing certain non-photosynthetic proteins (Wan et al., 1996; Yan et al., 2006; Primavesi et al., 2008). For example, only the transit peptide of the non-photosynthetic ferredoxin III and FtsZ precursors, but not that of the small subunit of RuBP carboxylase precursor (prRBCS), directs the import of GFP into leucoplasts in endosperms of transgenic wheat (Primavesi et al., 2008). Using leucoplasts isolated from caster seeds and chloroplasts isolated from pea leaves and the ratio of precursor to mature proteins after import as an assessment of import efficiency, it has been shown that prRBCS was imported preferentially into chloroplasts, while precursors to RuBP carboxylase activase (prRCA) and ferredoxin-NADP ${ }^{+}$oxidoreductase (prFNR) were imported equally well into both plastids (Wan et al., 1996). Using leucoplasts and chloroplasts isolated from pea roots and leaves, respectively, it has been shown that prRBCS could not be imported into leucoplasts at all while two other non-photosynthetic precursors could (Yan et al., 2006). The plastid selectivity is determined by the transit peptide of each precursor as swapping of transit peptides resulted in interchanged plastid preference (Wan et al., 1995, 1996; Yan et al., 2006). It has been suggested that the different substrate preferences of Toc159 and Toc132 may also account for the import preferences of the two plastids (Yan et al., 2006; Li and Teng, 2013). Indeed, in Arabidopsis, Toc159 is about 15-fold higher in leaves than in roots while Toc132 is only about fivefold higher in leaves (Ivanova et al., 2004). Furthermore, the toc159 knockout mutant has severe import defects in mesophyll-cell chloroplasts (Bauer et al., 2000) but imports proteins normally into root plastids (Yu and $\mathrm{Li}, 2001)$. On the other hand, toc132 toc120 double mutations cause structural abnormalities in root plastids (Kubis et al., 2004), and the toc132 mutant is a root gravitropism mutant (Stanga et al., 2009), supporting that Toc159 is more important for leaf chloroplasts and Toc132 is more important for root leucoplasts.

As a first step in characterizing the molecular mechanism of protein import into leucoplasts, we optimized the in vitro protein import system of isolated leucoplasts to improve import efficiency and to permit a more quantitative comparison between leucoplasts and chloroplasts. We found that leucoplasts have a different stoichiometry of translocon components compared to chloroplasts. Precursors we tested fell into at least three different degrees of preference toward chloroplasts in our in vitro import system.

\section{Materials and Methods}

\section{Plastid Isolation and Plastid Number Counting}

Leucoplasts and chloroplasts were prepared from pea seedlings (Pisum sativum cv. Green Arrow, De Bruyn Seed Co., Zeeland, MI, USA) grown at $20^{\circ} \mathrm{C}$ on vermiculite for $4-5$ days in the dark, and for 7 days under a $12-\mathrm{h}$ photoperiod with a light intensity of approximately $150 \mu \mathrm{mol} \mathrm{m} \mathrm{m}^{-2} \mathrm{~s}^{-1}$, respectively. Leucoplasts were prepared from pea roots as described (Bowsher et al., 1989) with modifications described below. Approximately $20 \sim 30 \mathrm{~g}$ of roots were collected and washed twice with $100 \mathrm{~mL}$ homogenization buffer (50 mM Tricine-KOH, pH 7.9, $330 \mathrm{mM}$ sorbitol, $1 \mathrm{mM} \mathrm{MgCl} 2,2 \mathrm{mM}$ EDTA) in the presence of $1 \%$ BSA and reducing agents $(2 \mathrm{mM}$ ascorbic acid, $0.1 \mathrm{mM}$ DTT, and $1.2 \mathrm{mM}$ glutathione). The roots were cut into small pieces in another $100 \mathrm{~mL}$ of the same buffer, and were homogenized with a domestic blender by two 5 -s pulses. The homogenate was filtered through four layers of Miracloth and centrifuged at $4,000 \mathrm{~g}$ for $3 \mathrm{~min}$ at $4^{\circ} \mathrm{C}$. The leucoplast pellet was resuspended with $10 \mathrm{~mL}$ of homogenization buffer, underlaid with $10 \mathrm{~mL}$ $10 \%$ (v/v) Percoll ${ }^{\mathrm{TM}}$ in TS buffer (50 mM Tricine-KOH, pH 7.9, $330 \mathrm{mM}$ sorbitol), and centrifuged with a swing-bucket rotor at $4,000 \mathrm{~g}$ for $5 \mathrm{~min}$ at $4^{\circ} \mathrm{C}$. The pellet was first washed with $30 \mathrm{~mL}$ TS buffer and again with $30 \mathrm{~mL}$ of import buffer $(50 \mathrm{mM}$ HEPES$\mathrm{KOH}, \mathrm{pH} 8.0,330 \mathrm{mM}$ sorbitol), by centrifugation at $4,000 \mathrm{~g}$ at $4^{\circ} \mathrm{C}$ for $3 \mathrm{~min}$. The final pellet was gently resuspended with $300 \mu \mathrm{L}$ of import buffer.

Chloroplast isolation from pea leaves was conducted as described (Perry et al., 1991) except $2 \mathrm{mM}$ ascorbic acid, $0.1 \mathrm{mM}$ DTT, and $1.2 \mathrm{mM}$ glutathione were added to the grinding buffer used for homogenization. Isolated chloroplasts were adjusted to $1 \mathrm{mg}$ chlorophyll $\mathrm{mL}^{-1}$ in import buffer.

To count the plastid number and estimate the plastid size, fractions of isolated leucoplast and chloroplast suspensions were counted in the Multisizer 3 Coulter Counter (Beckman Coulter) using a $30 \mu \mathrm{m}$-aperture tube. The same plastid preparations were subjected to BCA assays (Thermo) to determine the protein concentration. It is noted here that the sensitivity of the BCA assay is protein dependent (Smith et al., 1985) and since leucoplasts and chloroplasts have different protein compositions, which may affect the results of the determination. However, the 
assay should still be able to provide an estimation of the amount of proteins in the two plastids.

\section{Plasmid Construction and Translation of Precursors}

The coding region of soybean mitochondrial alternative oxidase precursor (prAOX, accession number X68702) was amplified from a soybean leaf cDNA pool by the forward primer AOXF1-XhoI ( $5^{\prime}$-gactcgagatgatgatgatgatgagccgc- $\left.3^{\prime}\right)$ and the reverse primer AOX-R1-SalI (5'-gcgtcgacttagtgataaccaattggagcagc- $\left.3^{\prime}\right)$. The PCR products were digested with XhoI and SalI and cloned into the XhoI/SalI site of pSP72. The sequence of prAOX was confirmed by sequencing and the plasmid was named pSP72-prAOX. The expression of prAOX was under the control of the SP6 promoter. Plasmids encoding prRBCS, pea prTic40, prFd-protA ${ }_{\text {His }}$ (Smith et al., 2004), prPDH E1 $\alpha$ (At1g01090), and prCpn10-2 (At3g60210) have been described (Teng et al., 2012). [ ${ }^{35}$ S] Met-labeled prPDH E1 $\alpha$ was generated by in vitro transcription for synthesizing RNA followed by in vitro translation using the rabbit reticulocyte lysate system (Promega). All other precursors were synthesized using the TNT Coupled Wheat Germ Extract or Reticulocyte Lysate system (Promega).

\section{Protein Import and Post-Import Analyses}

To compare import efficiency on an equal protein basis, $18 \mu \mathrm{L}$ $\left[{ }^{35} \mathrm{~S}\right]$ Met-labeled precursors were incubated with isolated plastids equivalent to $500 \mu \mathrm{g}$ proteins in the presence of $3 \mathrm{mM}$ ATP in import buffer in a final volume of $200 \mu \mathrm{L}$. To compare import efficiency on an equal plastid number basis, $113.67 \mu \mathrm{g}$ leucoplast proteins and $500 \mu \mathrm{g}$ chloroplast proteins were used instead. The import reactions were carried out at room temperature for $25 \mathrm{~min}$ and stopped by transferring to a new tube containing $1 \mathrm{~mL}$ cold import buffer. The plastids were pelleted at 3,000 $\mathrm{g}$ at $4^{\circ} \mathrm{C}$ for $3 \mathrm{~min}$ and resuspended in $200 \mu \mathrm{L}$ import buffer. The

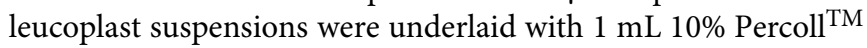
$(\mathrm{v} / \mathrm{v})$ in import buffer and the chloroplast suspensions were laid on top of a $40 \%$ Percoll $^{\mathrm{TM}}(\mathrm{v} / \mathrm{v})$ cushion and centrifuged in a swinging-bucket rotor at 2,900 $\mathrm{g}$ and $4^{\circ} \mathrm{C}$ for $6 \mathrm{~min}$ to isolate intact plastids. The plastids were washed once with import buffer. Thermolysin treatments of in vitro translation products and leucoplasts after import were performed as described (Perry et al., 1991), and intact leucoplasts were re-isolated as described above. Protein concentrations of the plastid samples were measured with the BCA kit (Thermo). Samples were analyzed by SDSPAGE. Quantification of gel bands was performed using the Fuji FLA5000 PhosphorImager (Fujifilm).

\section{Isolation of cDNA Encoding Partial Pea Toc132AG and Generation of Antibodies against Pea Toc132AG and OEP24}

Because the cDNA sequence of pea Toc132 was not available in the NCBI database, the Toc132 cDNA sequences from two closely related species, Medicago truncatula and Glycine max, were aligned and two highly conserved regions in the acidic domain (A domain) and GTPase domain (G domain) were chosen to design primers (Supplementary Figure S1A) for cloning. First-stand cDNA was synthesized from

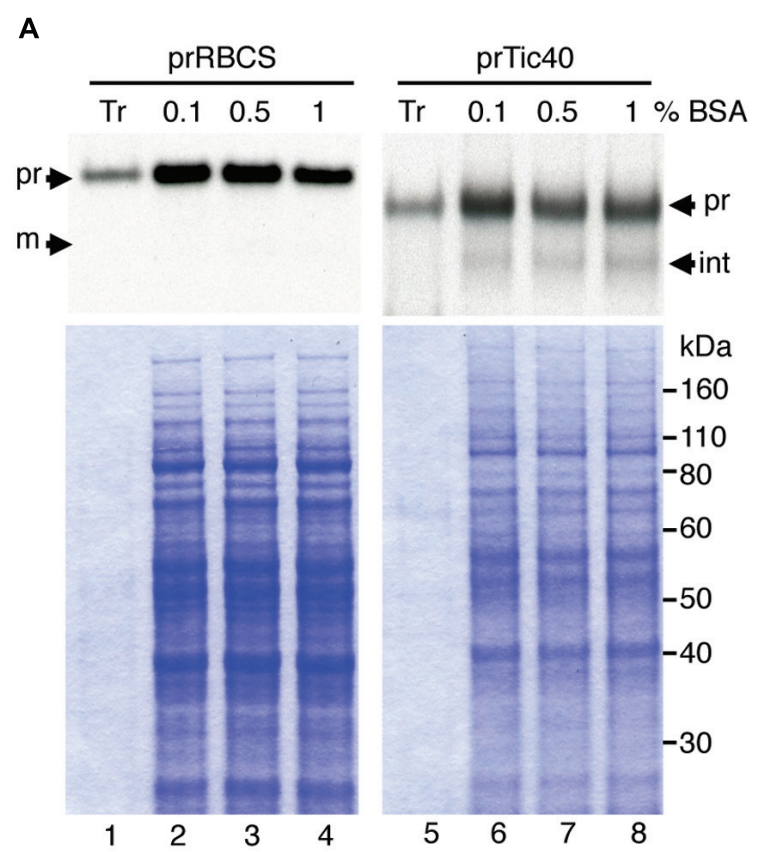

B

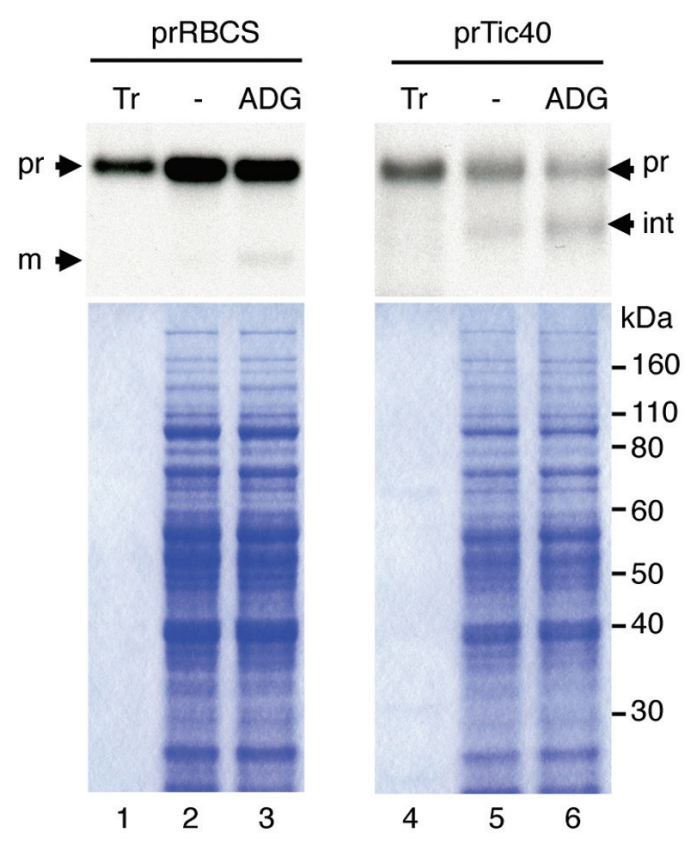

FIGURE 1 | Increasing BSA concentration and adding reducing agents to the homogenization buffer increases the import of prRBCS and prTic40 into leucoplasts. (A) Roots of 4-days-old pea seedlings grown in the dark were harvested and homogenized in homogenization buffer (see Materials and Methods) containing $0.1,0.5$, or $1 \%$ BSA. Isolated leucoplasts (500 $\mu \mathrm{g}$ protein) were then incubated with in vitro-translated $\left[{ }^{35}\right.$ S]Met-prRBCS or [ ${ }^{35}$ S]Met-prTic40 under import conditions for 25 min. After import, intact leucoplasts were re-isolated and analyzed by SDS-PAGE. The gels were stained with Coomassie blue and dried for fluorography. Twenty micrograms of proteins were loaded. Tr, $1 \%$ equivalent of the in vitro-translated proteins used in each import reaction. (B) Same as (A) except the homogenization buffer was supplemented with 1\% BSA, and with or without $2 \mathrm{mM}$ ascorbic acid, $0.1 \mathrm{mM}$ DTT, and $1.2 \mathrm{mM}$ glutathione (ADG). pr, precursor form; int, imported intermediate form; m, imported mature form. 
TABLE 1 | The sizes and protein contents of the isolated plastids.

\begin{tabular}{lll}
\hline Plastid type & $\begin{array}{l}\text { Plastid size } \\
(\boldsymbol{\mu} \mathbf{~ m})\end{array}$ & $\begin{array}{l}\text { Protein content } \\
\text { (pg/plastid) }\end{array}$ \\
\hline $\begin{array}{l}\text { Chloroplasts } \\
\text { (7-days-old light-grown leaves) }\end{array}$ & $3.24 \pm 0.23$ & $8.13 \pm 1.42$ \\
$\begin{array}{l}\text { Leucoplasts } \\
\text { (4-days-old dark-grown roots) }\end{array}$ & $1.81 \pm 0.21$ & $1.85 \pm 0.63$ \\
\hline
\end{tabular}

total pea-root RNA and used as templates to amplify the partial coding region of pea Toc132 A and $\mathrm{G}$ domains with the degenerate forward primer psToc132A-NdeI-F2 (5'gggcatatggawsttggagatgacaagatagagg- $\left.3^{\prime}\right)$ and the reverse primer psToc132G-XhoI-R1 ( $5^{\prime}$-gggctcgagtgcacttgcacgatcaaagctaaa- $\left.3^{\prime}\right)$. The sequence without the primer regions (Supplementary Figure $\mathrm{S1B})$ has been submitted to the GenBank and received the accession number KT033462. The PCR products were cloned into the $\mathrm{pCR}^{\mathrm{TM}}$-Blunt II-TOPO ${ }^{\circledR}$ (Invitrogen) to generate pTOPO-psToc132AG. After confirming the sequence, the DNA fragment of psToc132AG was excised by NdeI and XhoI from pTOPO-psToc132AG. Because the psToc132AG cDNA fragment has an endogenous XhoI site, only the longer psToc132 DNA fragment, in which XhoI cut at the XhoI site on the vector backbone, was subcloned into the NdeI and XhoI site of pET22b (Invitrogen) to generate the plasmid pET22bpsToc132AG-His 6 . The sequence was confirmed again and the pET22b-psToc132AG-His 6 plasmid was transformed into the Escherichia coli strain BL21 (DE3) for protein induction. Protein expression of psToc132AG-His 6 was induced by $1 \mathrm{mM}$ IPTG at $37^{\circ} \mathrm{C}$ for $3 \mathrm{~h}$, purified by TALON resins (CLONTECH Laboratories) with $50 \mathrm{mM}$ imidazole, dialyzed with $50 \mathrm{mM}$ Tris- $\mathrm{HCl}, \mathrm{pH} 8.0$, concentrated by Amicon Ultra-15 (Millipore) and used to raise the anti-Toc132 antibodies used in this study. During preparing the manuscript, another clone encoding a partial pea Toc132AG domains has been reported (Chang et al., 2014) and the amino acid sequence is different from the psToc132AG clone we obtained. Full-length pea OEP24 cDNA (EMBL accession number AJ001009) was amplified from a firststrand cDNA library of pea leaves and cloned into the NdeI/XhoI site of pET22b. OEP24 protein was then expressed and purified from E. coli and used for antibody production. Antibodies against other TOC and TIC proteins were prepared as described (Chou et al., 2003; Tu et al., 2004). Antibodies against cpHsc70 and Lhcb1 were purchased from Agrisera (AS08 348 and AS01 004, respectively), and the antibody against Arabidopsis plastid PGI was a gift of Dr. Jychian Chen.

\section{Results}

\section{Optimization of the Protocol for Leucoplast Isolation}

Several reports have described protein import into isolated leucoplasts (Wan et al., 1996; Yan et al., 2006). We first followed an established protocol to isolate leucoplasts from roots of pea seedlings grown for 4-5 days in the dark (Bowsher et al., 1989). Leucoplasts isolated from pea roots have been studied extensively.

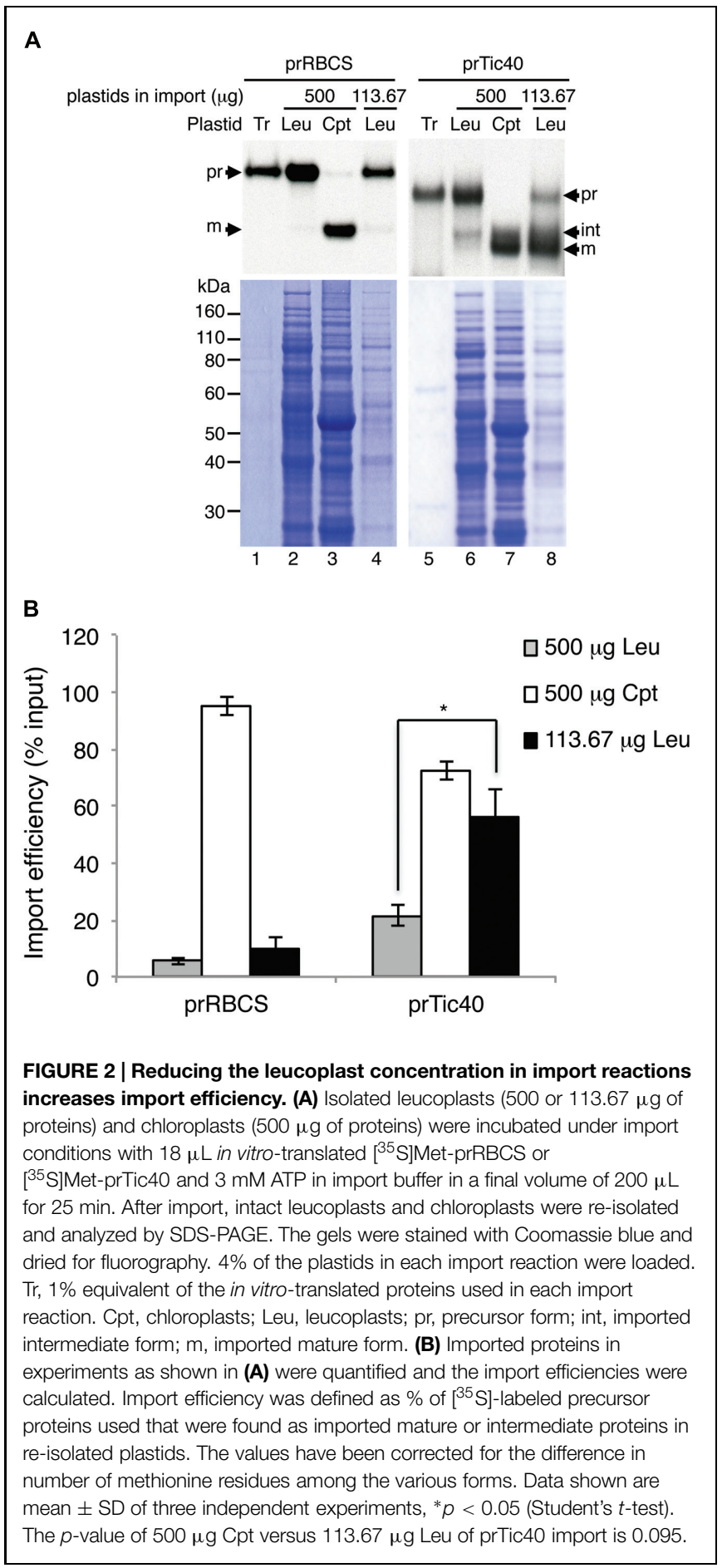

They are on average $2.5 \mu \mathrm{m}$ in diameter and contain starch grains, plastoglobuli, and also a few lamellae-type structures (Emes and England, 1986; Bowsher et al., 1989). When we tested the import of several precursor proteins from our collection, we found only prTic40 was imported and only to a small degree (data not shown). We therefore sought to improve the import efficiency of isolated leucoplasts. Because EDTA was reported to have a protective effect on recovering intact chloroplasts (Somerville 


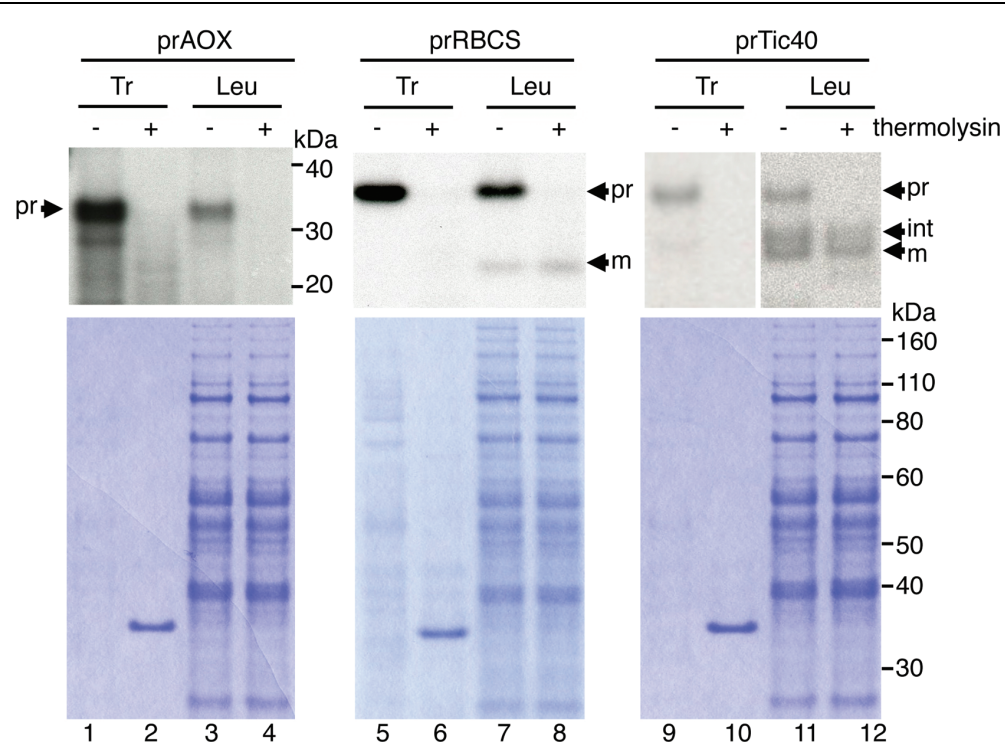

FIGURE 3 | The mitochondrial precursor protein prAOX was not imported into isolated leucoplasts. Isolated leucoplasts (113.67 $\mu$ g) were incubated with in vitro-translated $\left[{ }^{35} \mathrm{~S}\right] \mathrm{Met}-\mathrm{prAOX},\left[{ }^{35} \mathrm{~S}\right] \mathrm{Met}-$ prRBCS, or $\left[{ }^{35} \mathrm{~S}\right] \mathrm{Met}-\mathrm{prTic} 40$ under import conditions for 25 min. After import, the leucoplasts were treated with $0.2 \mathrm{mg} / \mathrm{mL}$ thermolysin for $30 \mathrm{~min}$ on ice, and intact leucoplasts were re-isolated and analyzed by SDS-PAGE. $4 \%$ of the plastids in each import reaction were loaded. The gels were stained with Coomassie blue and dried for fluorography. Tr, 1\% equivalent of the in vitro-translated proteins used in each import reaction. Leu, leucoplasts; pr, precursor form; int, imported intermediate form; m, imported mature form.

and Ogren, 1981) and BSA may protect plastids during isolation by limiting the activity of proteases (Seigneurin-Berny et al., 2008), we increased the concentrations of EDTA and BSA in the homogenization buffer. As shown in Figure 1A, the amount of processed Tic40 slightly increased and precursors associated with the leucoplasts slightly decreased with higher concentrations of BSA (Figure 1A, compare lanes 6-8). Precursors of Tic40 are processed twice upon import into chloroplasts, generating an intermediate and a mature form (Li and Schnell, 2006; Tripp et al., 2007). The leucoplast imported prTic40 we observed was mostly the intermediate form (Figure 1A, int). We also noticed that poor import occasionally occurred concomitant with dark brown leucoplast pellets. We surmised that some oxidative stress might have occurred during the isolation. It has been shown that pea roots contain a higher phenol oxidase activity than do pea leaves (Henry et al., 1979) and it is also possible that isolated leucoplasts are more sensitive to oxidative damages than do isolated chloroplasts. We therefore added reducing agents (2 $\mathrm{mM}$ ascorbic acid, $0.1 \mathrm{mM}$ DTT, and $1.2 \mathrm{mM}$ glutathione, designated as ADG in Figure 1B) to the homogenization buffer (Schulz et al., 2004; Aronsson and Jarvis, 2011). Indeed after adding the reducing agents, we no longer observed dark-brown leucoplast pellets and the import efficiency of prTic40 further increased (Figure 1B, lanes 5-6). Under the modified conditions, a very small amount of import could even be detected for prRBCS (Figure 1B, lane 3).

\section{Reducing the Number of Leucoplasts in Import Reactions Increases Import Efficiency}

After optimizing the leucoplast isolation conditions, we next tried to compare the import behaviors of various precursors into leucoplasts and chloroplasts. An equal amount of total proteins (Yan et al., 2006) or an equal number of plastids (Wan et al., 1996) was used as the basis when comparing import efficiencies of different plastids. To determine the number of plastids, the isolated leucoplasts and chloroplasts were counted using the Multisizer 3 Coulter Counter (Beckman Coulter). We used chloroplasts isolated from 7-days-old seedlings for robust import and to minimize the age difference between the leucoplast and chloroplast samples. From three independent preparations of leucoplasts and chloroplasts, the average size of the isolated leucoplasts and chloroplasts was estimated to be $1.81 \pm 0.21 \mu \mathrm{m}$ and $3.24 \pm 0.23 \mu \mathrm{m}$, respectively (Table 1). The same plastid preparations were then used for protein concentration determination and the average protein content per plastid was calculated to be $1.85 \pm 0.63$ and $8.13 \pm 1.42$ $\mathrm{pg} /$ plastid for leucoplasts and chloroplasts, respectively (Table 1). We then used protein content as an estimate of plastid numbers throughout our analyses. For example, $500 \mu \mathrm{g}$ of plastid proteins would represent approximately $2.71 \times 10^{8}$ leucoplasts and $6.15 \times 10^{7}$ chloroplasts. For import into chloroplasts, we used $500 \mu \mathrm{g}$ of chloroplasts $\left(\sim 6.15 \times 10^{7}\right.$ plastids $)$ in a $200 \mu \mathrm{L}$ import reaction. We then either used $500 \mu \mathrm{g}$ of leucoplasts for comparison on an equal protein basis or $113.67 \mu \mathrm{g}$ of leucoplasts $\left(\sim 6.15 \times 10^{7}\right.$ plastids) for comparison on an equal plastid number basis. After import, $4 \%$ of each import reaction was analyzed by SDS-PAGE. Interestingly, a lower concentration of leucoplasts (113.67 $\mu \mathrm{g} /$ reaction) in the import reactions resulted in a significant increase of prTic40 import efficiency (Figure 2A, compare lanes 6-8), compared to when $500 \mu \mathrm{g} /$ reaction were used, which was the amount we used for Figure 1. Using this lower leucoplast input, the import efficiency of prTic40 was 


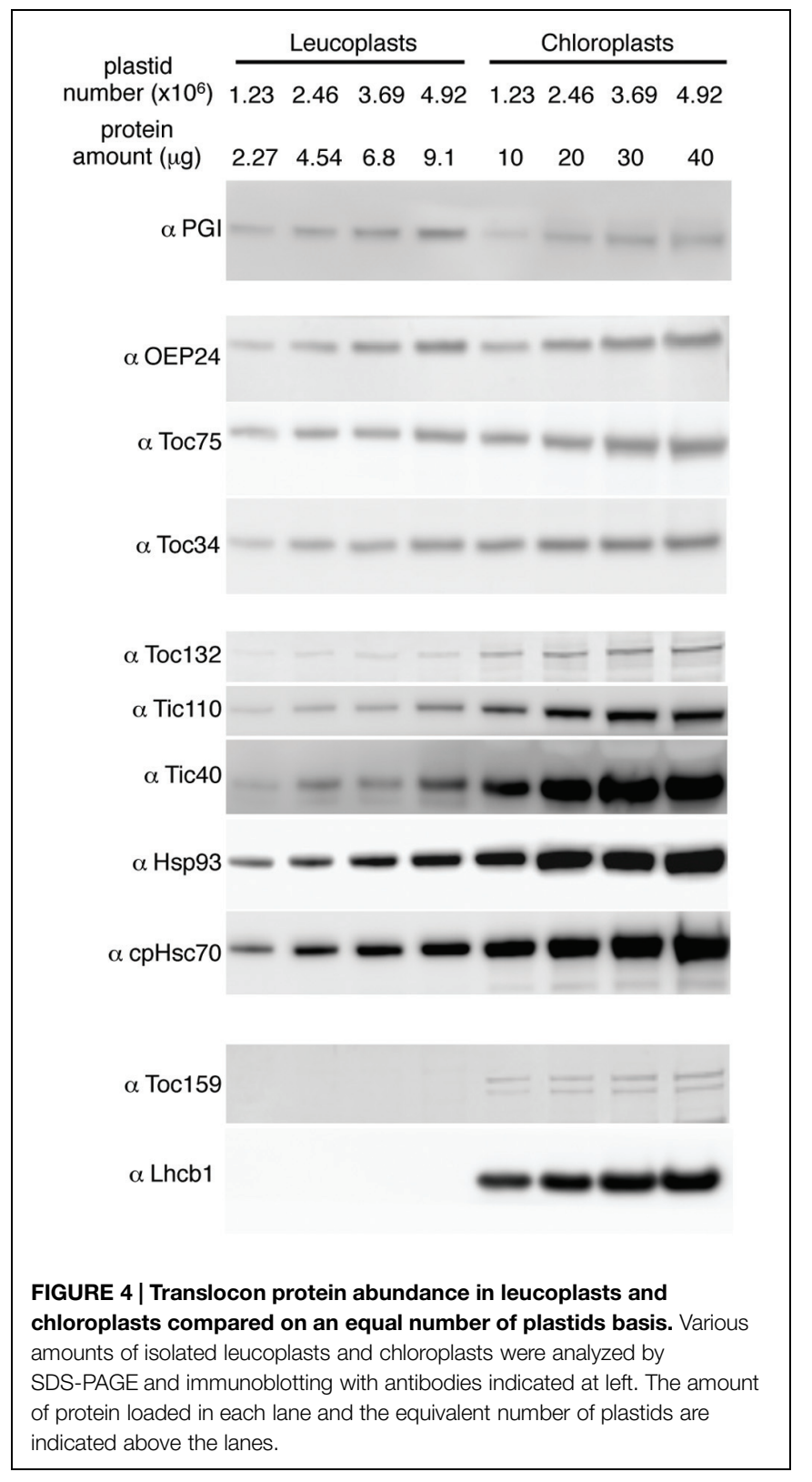

almost equal to its efficiency into chloroplasts and most of the imported proteins were in the mature form (Figure 2A, lanes 7 and 8). The import efficiency of prRBCS into leucoplasts was also slightly increased when a lower amount of leucoplasts was used, but the efficiency was still much lower than its efficiency into chloroplasts (Figures 2A, lanes 2-4, 2B). From these data, we decided to compare the import of different precursors into leucoplasts and chloroplasts on an equal plastid number basis in all subsequent analyses.

\section{Mitochondrial Precursor prAOX is not Imported into Isolated Leucoplasts}

The leucoplast preparations were reported to have about $1 \%$ contamination of mitochondria (Emes and England, 1986; Bowsher et al., 1989). Furthermore, it has been reported that chloroplast precursors can be imported into isolated pea mitochondria (Rudhe et al., 2002). To verify that the import we observed was not due to mis-sorting of plastid precursors to the mitochondria in the leucoplast preparation, we isolated cDNA clone encoding the soybean mitochondrial alternative oxidase precursor protein (prAOX), which is one of the most widely used precursor proteins for studying protein import into isolated plant mitochondria. The precursor form of prAOX is about $36 \mathrm{kDa}$. After being imported into isolated mitochondria, it is processed to a $32-\mathrm{kDa}$ mature protein, which is protected exogenously added protease (Whelan et al., 1995; Rudhe et al., 2002; Lister et al., 2007). [ $\left.{ }^{35} \mathrm{~S}\right]$ Met-labeled prAOX was synthesized and used in the leucoplast import assays as prTic40 and prRBCS. If the import we observed was due to import of prRBCS and prTic40 into the mitochondria in the leucoplast preparation, then a mitochondrial precursor like prAOX should import equally well or even better. As shown in Figure 3, although some prAOX signals were detected after import, these signals were degraded after treating the leucoplasts with thermolysin. No imported mature protein was detected even after over-exposure of the fluorograph (Figure 3, lanes 3 and 4). In contrast, both prRBCS and prTic40 produced mature proteins after import, and these mature proteins were thermolysin resistant, indicating that they were inside the leucoplasts (Figure 3, lanes 7, 8, 11, and 12).

\section{Most TOC/TIC Components are more Abundant in Chloroplasts than in Leucoplasts}

To investigate the translocon composition of leucoplasts, representative translocon proteins were analyzed by immunoblots. We used phosphoglucoisomerase (PGI), a plastid enzyme in the starch biosynthesis pathway and expressed in both leaves and roots, as a non-translocon stromal reference protein. We also used OEP24, a non-translocon plastid outer membrane protein expressed in both leaves and roots (Pohlmeyer et al., 1998), for a general assessment of the amount of the envelope proteins. When compared on the basis of an equal number of plastids, the amount of PGI in chloroplasts was similar or slightly lower than that in leucoplasts (Figure 4). The amount of OEP24 and the translocon proteins Toc75 and Toc34 was about $1.5 \mathrm{x}$ to $2.5 \mathrm{x}$ higher in chloroplasts than in leucoplasts. In comparison, abundances of Toc132, Tic110, Hsp93, cpHsc70, and Tic40 were much higher in chloroplasts. Toc159 is known to be extremely sensitive to protease and is easily degraded during plastid isolation (Bolter et al., 1998). In chloroplasts, we detected, in addition to the full-length Toc159, at least one lower molecular weight band that is most likely a partially degraded Toc159 fragments. We could not detect any full-length Toc159 either in our leucoplast preparation (Figure 4) or when roots were directly ground up in SDS-PAGE sample buffer in liquid nitrogen (data not shown). Very low amounts of smaller fragments were detected in leucoplasts (data not shown) but our antibody was not specific enough to exclude cross-reactivity with other Toc159 members. Nonetheless, even if Toc159 is present in the leucoplasts of pea roots, it is much less abundant than in chloroplasts. In addition, no chlorophyll $a / b$ binding protein of photosystem II (Lhcb1) could be detected, suggesting that our leucoplasts were not contaminated with chloroplasts. 
A

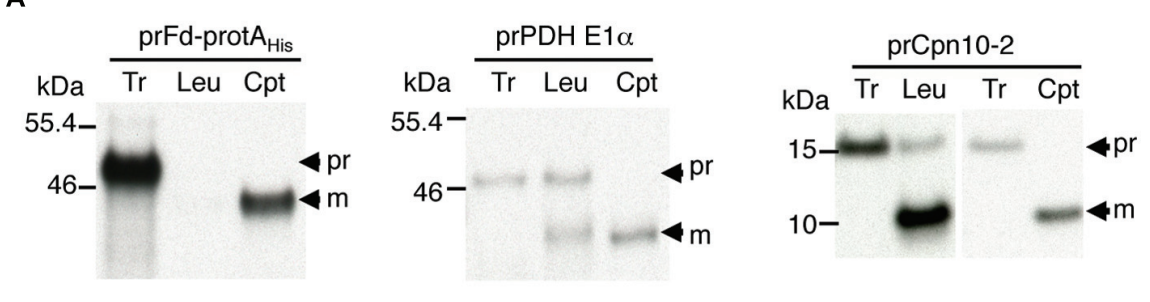

B

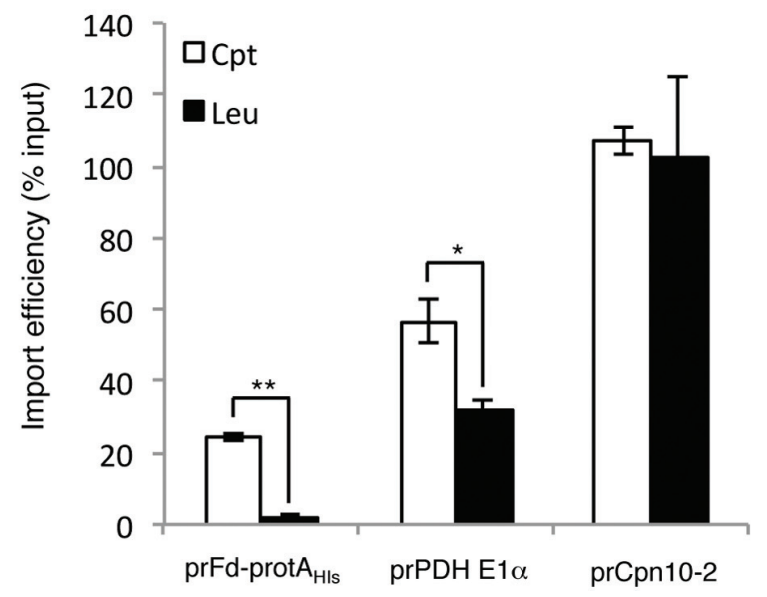

FIGURE 5 | Precursor proteins show different plastid preferences. (A) Isolated leucoplasts (113.67 $\mu \mathrm{g}$ protein) and chloroplasts (500 $\mu \mathrm{g}$ protein) were incubated with various in vitro-translated [ $\left.{ }^{35} \mathrm{~S}\right]$ Met-precursors under import conditions for 25 min. After import, intact leucoplasts and chloroplasts were re-isolated and analyzed by SDS-PAGE. The gels were stained with Coomassie blue and dried for fluorography. $4 \%$ of the plastids in each import reaction were loaded. Tr, $1 \%$ (for prFd-prot $\mathrm{A}_{\mathrm{His}}$ and prPDH E1 $\alpha$ ) or 1.2\% (for prCpn10-2) equivalent of the in vitro-translated proteins used in each import reaction. Cpt, chloroplasts; Leu, leucoplasts; pr, precursor form; m, imported mature form. (B) Imported mature proteins in experiments as shown in (A) were quantified and the import efficiencies were calculated. Import efficiency was defined as \% of [ $\left.{ }^{35} \mathrm{~S}\right]$-labeled precursor proteins used that were found as mature proteins in re-isolated plastids. The values have been corrected for the difference in number of methionine residues between the precursor and mature forms. Data shown are mean \pm SD of three independent experiments, ${ }^{*} p<0.05,{ }^{* *} p<0.001$ and the $p$-value of prCpn10-2 Cpt versus Leu is 0.67 (Student's $t$-test).

\section{Import of prFd-protA $\mathrm{His}_{\text {, }}$ prPDH E1 $\alpha$, and prCpn10-2 into Leucoplasts}

We had determined that pea root leucoplasts had a lower amount of Toc132 and almost no Toc159. If the interactions with these Toc159 family members contribute to plastid preference, a precursor that prefers Toc159 should import much better into chloroplasts, while a precursor that prefers Toc132 should exhibit a smaller difference. Our data with prRBCS indeed support this (Figure 2B). We further tested another two precursors that have been directly demonstrated to select between Toc159 and Toc132: the transit peptide of ferredoxin precursor ( $\mathrm{prFd}$ ) prefers Toc159 while the transit peptide of pyruvate dehydrogenase E1 $\alpha$ subunit precursor (prPDH E1 $\alpha$ ) prefers Toc132 (Ivanova et al., 2004; Smith et al., 2004; Inoue et al., 2010). For prFd, we used the construct prFd-prot $A_{H i s}$, which contains ferredoxin transit peptide fused to Staphylococcal protein A (protA; Smith et al., 2004). As shown in Figure 5, prFd-prot $A_{H i s}$ imported well into chloroplasts but was nearly undetectable in leucoplasts, similar to the results for prRBCS (Figure 2). In comparison, although prPDH E1 $\alpha$ also imported better into chloroplasts, its import was at least half as strong in leucoplasts in our in vitro system.
We further tested several additional precursors but did not find any precursors with higher import efficiency into leucoplasts than into chloroplasts in our system. However, we did find several precursors similar to prTic40 that exhibited no import bias between leucoplasts and chloroplasts in our in vitro system. One example was the precursor of chaperonin 10-2 (prCpn10-2), which imported very well into both chloroplasts and leucoplasts (Figure 5B). The import pathways prCpn10-2 and prTic40 used may be partially different from those of prRBCS and prPDH E1 $\alpha$.

\section{Discussion}

We performed initial quantifications of translocon components of pea root leucoplasts. Considering that the diameter of chloroplasts we used is about 1.7 times that of leucoplasts, the chloroplast surface area should be about three times that of leucoplasts. However, the amount of chloroplast Toc75 and Toc34 is only about twice that in leucoplasts. Therefore, the density of Toc75 and Toc34 is not necessarily higher in chloroplasts. If the non-translocon protein OEP24 is present in 
about the same density in chloroplasts and leucoplasts, then the density of Toc75 and Toc34 in the two plastids would also be similar. On the other hand, other essential translocon components, like Tic110, Hsp93 and cpHsc70, are clearly less abundant in leucoplasts. We did not analyze the amount of other essential components like Tic20 and Tic56 (Kikuchi et al., 2013; Köhler et al., 2015) due to unavailability of antibodies recognizing the pea orthologous well and their amounts in leucoplasts remain to be determined. However, based on our current data, it is likely that similar numbers of Toc75 and Toc34 subunits are coupled with lower numbers of other translocon components in leucoplasts. This composition may reflect that, under normal physiological conditions, the protein import demand of leucoplasts is not as high as young chloroplasts. Once precursors are bound to the TOC complex, leucoplasts can afford a lower import rate than chloroplasts.

It has been proposed that the precursor selectivity between leucoplasts and chloroplasts may also be due to the distinct substrate preference of Toc159 versus Toc132 (Yan et al., 2006; $\mathrm{Li}$ and Teng, 2013). We therefore tested the three precursors that have been directly shown to prefer one receptor to the other. In agreement with the much higher abundance of Toc159 in leaf chloroplasts, prRBCS and prFd-prot $\mathrm{A}_{\mathrm{His}}$, which show a preference for Toc159, also imported much better into chloroplasts. Toc132 is still more abundant in chloroplasts but is present in leucoplasts at a reasonable amount. And indeed, prPDH E1 $\alpha$, which shows a preference for Toc132, had a leucoplast import efficiency about $50 \%$ that of chloroplasts in our current in vitro system. Unfortunately the transit peptide of $\operatorname{prPDH} \mathrm{E} 1 \alpha$ is the only transit peptide that has been shown biochemically to prefer Toc132 over Toc159. The importance of Toc132 in leucoplast import will need to be tested with more precursors with clear preferences for Toc132.

We did not find any precursors with higher import efficiency into leucoplasts than into chloroplasts in our system. It is possible that our leucoplast in vitro import system is still not as optimized as that of chloroplasts. However, compared to prRBCS/prFd and $\operatorname{prPDH} \mathrm{E} 1 \alpha$, we found a third group of precursors that have similar import efficiencies into both plastids in our current in vitro system. Previous reports have indicated that prFNR, prRCA and the precursor of leucoplast pyruvate kinase also imported equally well into the two plastids (Wan et al., 1995, 1996). Although in those reports leucoplasts and chloroplasts were isolated from different species, it is likely that these precursors share some import characteristics with prTic40 and prCpn10-2 that we analyzed here. Unlike precursors that clearly prefer Toc159 or Toc132, the import of these precursors did not decline in leucoplasts. They may use some novel component present in similar amounts in the two plastids or they may simply bypass the need for the Toc159 family protein and use Toc34 and

\section{References}

Aronsson, H., and Jarvis, R. P. (2011). Rapid isolation of Arabidopsis chloroplasts and their use for in vitro protein import assays. Methods Mol. Biol. 774, 281-305. doi: 10.1007/978-1-61779-234-2_17
Toc75 directly. However, it is also possible that these precursors import into leucoplast through distinct pathways. It would be interesting to further study their import mechanism and identify the motifs in their transit peptides that confer efficient leucoplast import.

The transit peptide of prRBCS is the most widely used transit peptide for directing passenger proteins into plastids in transgenic plants, even when the passenger proteins were meant for non-green plastids like leucoplasts. For example, the prRBCS transit peptide was used to deliver the bacterial carotene desaturase into rice grain leucoplasts for the development of the Golden Rice (Ye et al., 2000; Paine et al., 2005). As shown here and other reports (Wan et al., 1996; Yan et al., 2006; Primavesi et al., 2008), the import efficiency of this transit peptide into leucoplasts is rather poor. The precursors that exhibited equally high efficiency into both chloroplasts and leucoplasts in our in vitro system, like prTic40 and prCpn10-2, offer promising potential that their transit peptides can confer better import of passenger proteins in transgenic plant leucoplasts than the prRBCS transit peptide. They could be valuable tools in manipulations of crops in which leucoplasts provide the major nutrient source.

\section{Author Contributions}

$\mathrm{C}-\mathrm{CC}$ and $\mathrm{H}-\mathrm{mL}$ designed the experiments and prepared the manuscript. C-CC performed the experiments.

\section{Acknowledgments}

We thank Dr. Tung-Yuan Ho for providing the Multisizer 3 for plastids counting, Ms. May-Jen Lu for technical assistance in using the counter, Dr. Danny Schnell for the prFd-protA $A_{H i s}$ construct, and Dr. Jychian Chen for the PGI antibodies. We also thank Ms. Ming-Yan Kuo for the preparation of the anti-OEP24 antibody, Ms. Po-Ting Chan for cloning the psToc132AG fragment and Mr. Yang-Tsung Lin for preparation of the psToc132AG protein and anti-psToc132AG antibody. We acknowledge the assistance of the Institute of Molecular Biology Scientific English Editing Core in preparing this manuscript. This work was supported by grants to $\mathrm{H}-\mathrm{mL}$ from Ministry of Science and Technology (MOST 103-2321-B-001-053) and Academia Sinica of Taiwan.

\section{Supplementary Material}

The Supplementary Material for this article can be found online at: http://journal.frontiersin.org/article/10.3389/fpls.2015.00690

Barsan, C., Zouine, M., Maza, E., Bian, W., Egea, I., Rossignol, M., et al. (2012). Proteomic analysis of chloroplast-to-chromoplast transition in tomato reveals metabolic shifts coupled with disrupted thylakoid biogenesis machinery and elevated energy-production components. Plant Physiol. 160, 708-725. doi: $10.1104 /$ pp.112.203679 
Bauer, J., Chen, K., Hiltbunner, A., Wehrli, E., Eugster, M., Schnell, D., et al. (2000). The major protein import receptor of plastids is essential for chloroplast biogenesis. Nature 403, 203-207. doi: 10.1038/35003214

Bauer, J., Hiltbrunner, A., Weibel, P., Vidi, P.-A., Alvarez-Huerta, M., Smith, M. D., et al. (2002). Essential role of the G-domain in targeting of the protein import receptor atToc159 to the chloroplast outer membrane. J. Cell Biol. 159, 845-854. doi: $10.1083 /$ jcb. 200208018

Bischof, S., Baerenfaller, K., Wildhaber, T., Troesch, R., Vidi, P. A., Roschitzki, B., et al. (2011). Plastid proteome assembly without Toc159: photosynthetic protein import and accumulation of $\mathrm{N}$-acetylated plastid precursor proteins. Plant Cell 23, 3911-3928. doi: 10.1105/tpc.111.092882

Bolter, B., May, T., and Soll, J. (1998). A protein import receptor in pea chloroplasts, Toc86, is only a proteolytic fragment of a larger polypeptide. FEBS Lett. 441, $59-62$.

Bowsher, C. G., Hucklesby, D. P., and Emes, M. J. (1989). Nitrite reduction and carbohydrate metabolism in plastids purified from roots of Pisum sativum L. Planta 177, 359-366. doi: 10.1007/BF00403594

Brautigam, A., and Weber, A. P. (2009). Proteomic analysis of the proplastid envelope membrane provides novel insights into small molecule and protein transport across proplastid membranes. Mol. Plant 2, 1247-1261. doi: $10.1093 / \mathrm{mp} / \mathrm{ssp} 070$

Chang, W., Soll, J., and Bolter, B. (2014). A new member of the psToc159 family contributes to distinct protein targeting pathways in pea chloroplasts. Front. Plant Sci. 5:239. doi: 10.3389/fpls.2014.00239

Chou, M. L., Fitzpatrick, L. M., Tu, S. L., Budziszewski, G., Potter-Lewis, S., Akita, M., et al. (2003). Tic40, a membrane-anchored co-chaperone homologue in the chloroplast protein translocon. EMBO J. 22, 2970-2980. doi: 10.1093/emboj/cdg281

Emes, M. J., and England, S. (1986). Purification of plastids from higher plant roots. Planta 168, 161-166. doi: 10.1007/BF00402959

Henry, E. W., DeMorrow, J. M., and Richard, L. B. (1979). The effects of phenolic compounds on peroxidase and polyphenol oxidase in dwarf pea (Pisum sativum var. Little marvel) tissue. Z. Pflanzenphysiol. 92, 221-239. doi: 10.1016/S0044328X(79)80004-5

Inoue, H., Rounds, C., and Schnell, D. J. (2010). The molecular basis for distinct pathways for protein import into Arabidopsis chloroplasts. Plant Cell 22, 1947-1960. doi: 10.1105/tpc.110.074328

Ivanova, Y., Smith, M. D., Chen, K., and Schnell, D. J. (2004). Members of the Toc159 import receptor family represent distinct pathways for protein targeting to plastids. Mol. Biol. Cell 15, 3379-3392. doi: 10.1091/mbc.E0312-0923

Jarvis, P., and Lopez-Juez, E. (2013). Biogenesis and homeostasis of chloroplasts and other plastids. Nat. Rev. Mol. Cell Biol. 14, 787-802. doi: 10.1038/nrm3702

Kikuchi, S., Bedard, J., Hirano, M., Hirabayashi, Y., Oishi, M., Imai, M., et al. (2013). Uncovering the protein translocon at the chloroplast inner envelope membrane. Science 339, 571-574. doi: 10.1126/science. 1229262

Kleffmann, T., von Zychlinski, A., Russenberger, D., Hirsch-Hoffmann, M., Gehrig, P., Gruissem, W., et al. (2007). Proteome dynamics during plastid differentiation in rice. Plant Physiol. 143, 912-923. doi: 10.1104/pp.106.0 90738

Köhler, D., Montandon, C., Hause, G., Majovsky, P., Kessler, F., Baginsky, S., et al. (2015). Characterization of chloroplast protein import without Tic56, a component of the 1-megadalton translocon at the inner envelope membrane of chloroplasts. Plant Physiol. 167, 972-990. doi: 10.1104/pp.114.255562

Kubis, S., Patel, R., Combe, J., Bedard, J., Kovacheva, S., Lilley, K., et al. (2004). Functional specialization amongst the Arabidopsis Toc159 family of chloroplast protein import receptors. Plant Cell 16, 2059-2077. doi: 10.1105/tpc.104.023309

Leister, D. (2003). Chloroplast research in the genomic age. Trends Genet. 19, 47-56. doi: 10.1016/S0168-9525(02)00003-3

Li, H.-m., and Chiu, C. C. (2010). Protein transport into chloroplasts. Annu. Rev. Plant Biol. 61, 157-180. doi: 10.1146/annurev-arplant-042809-112222

Li, H.-m., and Teng, Y. S. (2013). Transit peptide design and plastid import regulation. Trends Plant Sci. 18, 360-366. doi: 10.1016/j.tplants.2013.04.003

Li, M., and Schnell, D. J. (2006). Reconstitution of protein targeting to the inner envelope membrane of chloroplasts. J. Cell Biol. 175, 249-259. doi: $10.1083 /$ jcb. 200605162

Lister, R., Carrie, C., Duncan, O., Ho, L. H., Howell, K. A., Murcha, M. W., et al. (2007). Functional definition of outer membrane proteins involved in preprotein import into mitochondria. Plant Cell 19, 3739-3759. doi: 10.1105/tpc.107.050534

Paila, Y. D., Richardson, L. G., and Schnell, D. J. (2015). New insights into the mechanism of chloroplast protein import and its integration with protein quality control, organelle biogenesis and development. J. Mol. Biol. 427, 1038-1060. doi: 10.1016/j.jmb.2014.08.016

Paine, J. A., Shipton, C. A., Chaggar, S., Howells, R. M., Kennedy, M. J., Vernon, G., et al. (2005). Improving the nutritional value of Golden Rice through increased pro-vitamin A content. Nat. Biotechnol. 23, 482-487. doi: 10.1038/nb t1082

Perry, S. E., Buvinger, W. E., Bennett, J., and Keegstra, K. (1991). Synthetic analogues of a transit peptide inhibit binding or translocation of chloroplastic precursor proteins. J. Biol. Chem. 266, 11882-11889.

Pohlmeyer, K., Soll, J., Grimm, R., Hill, K., and Wagner, R. (1998). A highconductance solute channel in the chloroplastic outer envelope from Pea. Plant Cell 10, 1207-1216. doi: 10.1105/tpc.10.7.1207

Primavesi, L. F., Wu, H., Mudd, E. A., Day, A., and Jones, H. D. (2008). Visualisation of plastids in endosperm, pollen and roots of transgenic wheat expressing modified GFP fused to transit peptides from wheat SSU RubisCO, rice FtsZ and maize ferredoxin III proteins. Transgenic Res. 17, 529-543. doi: 10.1007/s11248-007-9126-7

Rudhe, C., Chew, O., Whelan, J., and Glaser, E. (2002). A novel in vitro system for simultaneous import of precursor proteins into mitochondria and chloroplasts. Plant J. 30, 213-220. doi: 10.1046/j.1365-313X.2002.01280.x

Sakamoto, W., Miyagishima, S. Y., and Jarvis, P. (2008). Chloroplast biogenesis: control of plastid development, protein import, division and inheritance. Arabidopsis Book 6, e0110. doi: 10.1199/tab.0110

Schulz, A., Knoetzel, J., Scheller, H. V., and Mant, A. (2004). Uptake of a fluorescent dye as a swift and simple indicator of organelle intactness: import-competent chloroplasts from soil-grown Arabidopsis. J. Histochem. Cytochem. 52, 701-704. doi: 10.1177/002215540405200514

Seigneurin-Berny, D., Salvi, D., Joyard, J., and Rolland, N. (2008). Purification of intact chloroplasts from Arabidopsis and spinach leaves by isopycnic centrifugation. Curr. Protoc. Cell Biol. Chap. 3, Unit 3.30. doi: 10.1002/0471143030.cb0330s40

Shi, L. X., and Theg, S. M. (2013). The chloroplast protein import system: from algae to trees. Biochim. Biophys. Acta 1833, 314-331. doi: 10.1016/j.bbamcr.2012.10.002

Smith, M. D., Rounds, C. M., Wang, F., Chen, K., Afitlhile, M., and Schnell, D. J. (2004). atToc159 is a selective transit peptide receptor for the import of nucleus-encoded chloroplast proteins. J. Cell Biol. 165, 323-334. doi: $10.1083 /$ jcb. 200311074

Smith, P. K., Krohn, R. I., Hermanson, G. T., Mallia, A. K., Gartner, F. H., Provenzano, M. D., et al. (1985). Measurement of protein using bicinchoninic acid. Anal. Biochem. 150, 76-85. doi: 10.1016/0003-2697(85)90442-7

Somerville, C. R., and Ogren, W. L. (1981). Photorespiration-deficient mutants of Arabidopsis thaliana lacking mitochondrial serine transhydroxymethylase activity. Plant Physiol. 67, 666-671. doi: 10.1104/pp.67.4.666

Stanga, J. P., Boonsirichai, K., Sedbrook, J. C., Otegui, M. S., and Masson, P. H. (2009). A role for the TOC complex in Arabidopsis root gravitropism. Plant Physiol. 149, 1896-1905. doi: 10.1104/pp.109.135301

Teng, Y. S., Chan, P. T., and Li, H.-m. (2012). Differential age-dependent import regulation by signal peptides. PLoS Biol. 10:e1001416. doi: 10.1371/journal.pbio.1001416

Tripp, J., Inoue, K., Keegstra, K., and Froehlich, J. E. (2007). A novel serine/prolinerich domain in combination with a transmembrane domain is required for the insertion of AtTic40 into the inner envelope membrane of chloroplasts. Plant J. 52, 824-838. doi: 10.1111/j.1365-313X.2007.03279.x

Tu, S. L., Chen, L. J., Smith, M., Su, Y.-S., Schnell, D., and Li, H.-m. (2004). Import pathways of chloroplast interior proteins and the outermembrane protein OEP14 converge at Toc75. Plant Cell 16, 2078-2088. doi: 10.1105/tpc.104.023952

Wan, J., Blakeley, S. D., Dennis, D. T., and Ko, K. (1995). Import characteristics of a leucoplast pyruvate kinase are influenced by a 19-amino-acid domain within the protein. J. Biol. Chem. 270, 16731-16739. doi: 10.1074/jbc.270.28. 16731

Wan, J., Blakeley, S. D., Dennis, D. T., and Ko, K. (1996). Transit peptides play a major role in the preferential import of proteins into leucoplasts 
and chloroplasts. J. Biol. Chem. 271, 31227-31233. doi: 10.1074/jbc.271.49. 31227

Whelan, J., Hugosson, M., Glaser, E., and Day, D. A. (1995). Studies on the import and processing of the alternative oxidase precursor by isolated soybean mitochondria. Plant Mol. Biol. 27, 769-778. doi: 10.1007/BF00020229

Wise, R. R. (2006). "The diversity of plastid form and function," in The Structure and Function of Plastids, eds R. R. Wise and J. K. Hoober (Dordrecbt: Springer Netherlands).

Yan, X., Khan, S., Hase, T., Emes, M. J., and Bowsher, C. G. (2006). Differential uptake of photosynthetic and non-photosynthetic proteins by pea root plastids. FEBS Lett. 580, 6509-6512. doi: 10.1016/j.febslet.2006.10.057

Ye, X., Al-Babili, S., Kloti, A., Zhang, J., Lucca, P., Beyer, P., et al. (2000). Engineering the provitamin A (beta-carotene) biosynthetic pathway into (carotenoid-free) rice endosperm. Science 287, 303-305. doi: $10.1126 /$ science.287.5451.303
Yu, T.-S., and Li, H.-m. (2001). Chloroplast protein translocon components atToc159 and atToc33 are not essential for chloroplast biogenesis in guard cells and root cells. Plant Physiol. 127, 90-96. doi: 10.1104/pp. 127.1 .90

Conflict of Interest Statement: The authors declare that the research was conducted in the absence of any commercial or financial relationships that could be construed as a potential conflict of interest.

Copyright (c) 2015 Chu and Li. This is an open-access article distributed under the terms of the Creative Commons Attribution License (CC BY). The use, distribution or reproduction in other forums is permitted, provided the original author(s) or licensor are credited and that the original publication in this journal is cited, in accordance with accepted academic practice. No use, distribution or reproduction is permitted which does not comply with these terms. 